\title{
7) Memorias para armar. Las conmemoraciones del 24 de Marzo en escuelas primarias del conurbano bonaerense
}

\author{
Gonzalo de Amézola y Claudia D'Achary ${ }^{2}$
}

\section{Historia reciente, memoria y escuela}

\begin{abstract}
A fines de 2006, el Congreso aprobó la Ley de Educación NacioA nal que reemplazó a la controvertida Ley Federal de Educación, vigente desde 1993. Entre las novedades que introdujo la nueva norma se encuentra la prescripción en su artículo 92 de algunos contenidos que debían ser de enseñanza obligatoria en todas las jurisdicciones. Uno de ellos se encuentra en el inciso " $c$ ", que establece que todas las escuelas debían ocuparse de: "El ejercicio y construcción de la memoria colectiva sobre los procesos históricos y políticos que quebraron el orden constitucional y terminaron instalando el terrorismo de Estado, con el objeto de generar en los/las alumnos/as reflexiones y sentimientos democráticos y de defensa del Estado de Derecho y la plena vigencia de los Derechos Humanos (...)"3.Con esta redacción se buscó sobre todo dar un lugar de relevancia al estudio de la dictadura que detentó el poder entre 1976 y $1983^{4}$.
\end{abstract}

1 Gonzal o deAmézola es profesor delaUNLP y delaUNGS. El presentetrabajo forma partedel Proyecto "Historia reciente y memoria. La memoria y las memorias en los discursos escolares", acreditado por la Universidad Nacional de General Sarmiento y del Proyecto "La historia de tiempo presente, la memoria colectiva y su transmisión en el espacio escolar", Universidad Nacional de La Plata, Programa de Incentivos a la Investigación, ambos dirigidos por Gonzalo deAmézola, email: gonzal odeamezola@speedy.comar.

2 Claudia D'Achary es becaria del Programa de Investigación y Docencia para Graduados Recientes delaUNGS.

3 Cfr: Ley deEducación Nacional (Ley N²6.206). Art. 92, inc. c, en www.me. gov.ar.

4 El anteproyecto de ley sólo se refería al golpe 1976-83, lo que luego es modificado en la redacción definitiva. Cfr. Ministerio de Educación. Ley de Educación Nacional. Anteproyecto de Ley, septiembre de 2006: 46. 
Esta preocupación por el tratamiento del pasado reciente no era, sin embargo, una innovación absoluta. Antes de 1993 los acontecimientos cercanos ya estaban presentes en los programas de estudios aunque constituían un apéndice tan reducido como poco frecuentado al final de los manuales y los planes de Historia. El gran cambio se produjo con la reforma de los 90, cuando el centro de gravedad de la historia escolar pasó de la primera mitad del siglo XIX a los acontecimientos contemporáneos y aún a los más recientes. Desde entonces, la trágica experiencia de nuestra sociedad durante la última dictadura militar ganó un creciente espacio en el currículo. Pero la incorporación en ese momento del tema en la Ley de Educación Nacional en 2006 adquiere una significación especial porque en marzo de ese año, al cumplirse el trigésimo aniversario del último golpe de Estado, el gobierno estableció que esa fecha sería considerada en adelante como Día de la Memoria por la Justicia y la Verdad, constituyéndose en un nuevo feriado nacional de carácter inamovible. A partir de entonces, además de figurar en los contenidos curriculares, la dictadura tendría un peso insoslayable en las conmemoraciones escolares. U na cuestión relevante acerca de esa presencia es cómo aparecería el tema en los actos escolares, qué conocimientos de aquel pasado se pondrían en juego y, sobre todo, qué representaciones de la memoria colectiva se transmitirían a los alumnos.

Al decidir la incorporación de la historia reciente se introduce a la escuela en una controversia aún no saldada entre los académicos. Para muchos de ellos, la pretensión de analizar el pasado inmediato sólo se consideraba pertinente para otras disciplinas sociales pero no para el análisis histórico, porque para que éste fuera posible se suponía debía mantener -como se estableció en el siglo XIX- una conveniente distancia temporal de los acontecimientos analizados. U no los más agudos objetores de la historia reciente como un campo de estudios autónomo fue Reinhart Kosellek, para quien: "Toda historia fue, es y será historia del tiempo presente. (...) En el nivel de nuestra formulación teórica podría afirmarse lo siguiente: la llamada historia del tiempo presente no se distingue en modo alguno de las otras historias que han tenido lugar y que han sido contadas" (Kosellek 2001:119).

Sin embargo, a pesar de las impugnaciones, la historia reciente se desarrolló desde la segunda posguerra y el interés que despierta en historiadores y público no especializado se incrementó en los últimos años. Pero tras esta aceptación se oculta otro problema: los partidarios 
de historiar el pasado próximo suelen tener criterios diversos acerca de lo que comprende su objeto, en cómo estudiarlo y en qué se puede obtener de su conocimiento. U na manifestación de estas discrepancias aparece cuando para denominarlo utilizan diversas fórmulas: $\mathrm{H}$ istoria del tiempo presente, $\mathrm{H}$ istoria inmediata, $\mathrm{H}$ istoria reciente, $\mathrm{H}$ istoria coetánea, Historia actual, Historia muy contemporánea, etc. Esta diversidad de rótulos encubre diferencias sustanciales y esas discrepancias muestran el carácter particularmente elusivo del concepto.

A primera vista, sería razonable definir lo reciente por su proximidad en el tiempo, pero la solución no es tan sencilla porque cuando el concepto de Historia del Tiempo Presente comenzó a emplearse en la década de los ' 70 no hacía referencia a cuestiones demasiado inmediatas. En Francia, apareció con el descubrimiento de que la conformidad con la ocupación nazi durante la Segunda Guerra Mundial había sido mucho más extendida de lo que se había querido creer en la posguerra. En Alemania, por la necesidad de explicar el Holocausto. En España, por la tragedia de la Guerra Civil. Estas preocupaciones continúan siendo centrales hoy para la "historia del tiempo presente" de estos países aunque ya hayan transcurrido unos setenta años de que aquellos acontecimientos se produjeran. Sin duda, hay muchos temas relevantes más cercanos en el tiempo que los mencionados en el pasado de esas naciones, pero son aquellos los que concentran todavía el interés de la historia reciente porque en los más modernos "algo" falta. En realidad, para la mayoría de los historiadores la historia del tiempo presente se define por los traumas que ese pasado aún proyecta sobre la actualidad. Henry Rousso acude a una definición que es una suerte de boutade sobre las diferentes temporalidades de Fernand Braudel y sostiene que la historia reciente se ocupa de los "acontecimientos de larga duración" porque en el corazón y la cabeza de quienes viven en la actualidad estos hechos aún siguen vivos, aún no han concluido, sus repercusiones se hacen sentir todavía en el presente (Feld 2000) En el caso de nuestro país, ese pasado no cicatrizado es para la mayoría el período de la última dictadura militar.

En conclusión, la escuela sin advertirlo incluye el tratamiento de una porción del pasado cuya pertinencia es debatida por los historiadores y que, aún entre quienes lo aceptan, presenta diferencias en cómo entenderlo. Por supuesto que este no es un argumento para eludir esos temas pero sí para tener en cuenta cuando deban tratarse estas cuestiones en las aulas. Sin embargo, el problema no termina allí por- 
que cuando la Ley de 2006 establece que la escuela debe contribuir a la "construcción de la memoria colectiva", podría entenderse que memoria e Historia resultan para ella sinónimos.

Si bien está fuera de discusión que la memoria es la matriz de la Historia, esta última no tiene como único cometido preservar a aquélla. Una función capital de la Historia es la de problematizar a la memoria. Paul Ricoeur establece entre ambos conceptos tres diferencias. La primera es que la memoria se fundamenta en el testimonio y en la credibilidad del testigo, mientras que la Historia se basa en documentos que pueden y deben someterse a la crítica. La segunda es que el testimonio cuenta la inmediatez de la experiencia, mientras que la Historia puede ir más allá del conocimiento directo de los propios protagonistas y establecer regularidades y causas que ellos mismos no pudieron percibir por estar inmersos en esos sucesos. La tercera es que, mientras la memoria aspira a la fidelidad, el fin último de la $\mathrm{H}$ istoria es la verdad (Ricoeur 2004).

Una cuestión de interés es la advertencia que plantea Andreas Huyssen: "La memoria colectiva no es natural: siempre ha sido una construcción, como los mitos nacionales. (...) No una invención, porque está ligada a las raíces de la cultura, a lo vivido, pero tampoco una 'esencia' que perdura aunque uno no se preocupe por ella" (Costa 2002). También numerosos historiadores han manifestado preocupación por las mitificaciones que promueve un culto acrítico de la memoria. Alain Prost, por ejemplo, afirma que: “(...) el sentido de las conmemoraciones se pierde si un conocimiento culto no lo sustituye con rigor y piedad. Es preciso que en lo sucesivo, la $\mathrm{H}$ istoria tome el lugar de la memoria" (Prost 1999).

\section{Las memorias de la dictadura}

Las formas de transmitir el pasado producen fervientes discusiones y distanciamientos entre la historiografía, la memoria colectiva que constituye el imaginario social y la institución escolar. El escenario se complica aún más cuando el tema en cuestión es el terrorismo de Estado durante el último gobierno militar, ya que las modalidades que adoptaron los discursos públicos explicando esta cuestión resultan de los cruces entre la política y la historia a partir de los cuales se pueden 
reconocer diversas narraciones de la memoria que predominaron a través de las últimas décadas 5 .

La dictadura justificó su asalto al poder en 1976 por el "agotamiento de las instancias del mecanismo constitucional" y "la ausencia de ejemplos éticos y morales". Ante ese panorama, las Fuerzas Armadas - según su propio relato- habían cumplido con la obligación irrenunciable de erradicar la subversión. En estos "actos de servicio" en la "guerra sucia" se incurrió en los "errores y excesos" que resultan siempre inevitables en todo conflicto armado ${ }^{6}$. Esta narrativa justificaba la represión ilegal a partir de los ' 70 por la violencia previa de las organizaciones armadas, ya que se adjudicaba a ellas exclusivamente la creación de las condiciones que hicieron imprescindible que las Fuerzas Armadas tomaran el gobierno para restablecer el orden.

Hacia 1984 las denuncias de los organismos de Derechos H umanos y la investigación Ilevada a cabo por la Comisión $\mathrm{N}$ acional sobre la Desaparición de Personas (CONADEP), probaron que en vez de incurrir en "errores y excesos" los militares habían puesto en marcha un plan sistemático de secuestro, tortura y asesinato. La sociedad se preguntó entonces qué había ocurrido en realidad en aquella época y comenzó a reclamar respuestas para confrontar ese pasado. Así, la revisión del terrorismo de Estado se convirtió en una instancia clave para la construcción del futuro y se volvió urgente producir un consenso extendido que diera forma a un nuevo tipo de memoria asociada a los valores de la democracia. La narrativa que se produjo entonces como resultado de este reclamo fue la que más tarde se denominó "teoría de los dos demonios"7. Esta interpretación, que habitualmente

5 El concepto "memoria" es ciertamente pol isémico. Para el in, la memoria puede considerarse en una faz "habitual" (comportamientos regulares, hábitos y formas de expresión compartidos socialmente) y en su dimensión "narrativa", es decir, como capacidad de elaborar sentidos sobre el pasado donde operan la selección y el olvido (J elin 2002).

6 Este discurso militar, enunciado en comunicados iniciales y reafirmado en su proyecto de autoamnistía al final de la dictadura, fue sedimentando en una "vulgata procesista" que ha ido reapareciendo a lo largo de los años (Lorenz 2005).

7 Hugo Vezzetti demuestra que la representación social de los dos demonios estaba instalada en la opinión pública por lo menos desde 1974 y había si do expresada por Perón, el peronismo, la UCR, la izquierda (comuni sta, maoísta y trotskista), la I glesia, etc. También fue empleada por laAPDH y en el informe de la CIDH (Vezzetti 2009). 
se atribuye al informe de la CO NADEP ${ }^{8}$, se constituyó en un discurso que fue utilizado para ubicar a la sociedad como espectadora y víctima de lo ocurrido, ya que - se sostenía- había resultado perjudicada por una guerra a la que le resultaba ajena entre dos grupos armados: los militares de un lado y los guerrilleros del otro. La etapa fue acompañada por una exposición mediática de hallazgos de fosas comunes, testimonios de víctimas, etc. que se dio en llamar "el show del horror". En definitiva, la "teoría de los dos demonios" resultó un potente relato explicativo pero tuvo su costo: clausuró el necesario debate acerca de los consensos, conformidades y complicidades que tuvo la sociedad civil con la dictadura.

Los levantamientos "carapintada" de 1987 -promovidos por oficiales que se negaban a comparecer ante los jueces por su participación en el terrorismo de Estado- puso en evidencia la fragilidad del Poder Ejecutivo Nacional para sostener su política de derechos humanos y, aún, la estabilidad de las instituciones. Estas circunstancias impulsaron al Dr. Alfonsín a sancionar las leyes de "punto final" y "obediencia debida". A esta situación se sumó en 1989 una crisis económica con hiperinflación y saqueos masivos que instaló en la sociedad el temor al caos. A inicios de su gestión, el sucesor de Alfonsín, Carlos Ménem, potenció el movimiento regresivo en la política de derechos humanos. Generó así una nueva narrativa de la memoria colectiva: "la teoría de la reconciliación nacional", que proponía olvidar las tragedias del pasado como única forma de avanzar hacia el futuro. Esta fue la justificación explícita de los indultos que el Presidente firmó en 1989 y 1990.

A mediados de los 90 comenzó un nuevo ciclo de memoria promovido por distintos grupos que se oponían a la "conciliación nacional" del gobierno. El ejemplo emblemático de esta "contramemoria" fue el accionar de la agrupación HIJOS, lo que marcó para Gabriela Cerruti "el punto de inflexión en la arena de los derechos humanos"

8 La consideración del Nunca Más como ejemplo de la narrativa de los dos demonios puede ser discutido. Si bien es cierto que en su prólogo alude a una Argentina "convulsionada por un terror que provenía tanto desde la extrema derecha como de la extrema izquierda", también afirma que "a los delitos de los terroristas, las Fuerzas Armadas respondieron con un terrorismo infinitamente peor que el combatido, porque desde el 24 de marzo de 1976 contaron con el poderío y la impunidad del Estado absol uto, secuestrando, torturando y asesinando a miles de seres humanos" (Comisión Nacional sobre la Desaparición de Personas 1984:8). Además, el Nunca Más, en tanto informe, presenta las evidencias del terrorismo de Estado impuesto en la dictadura y no de los "dos terrorismos". 
(Cerruti 2001:21). Paralelamente se conoció la voz del ex capitán de corbeta Adolfo Scilingo (Verbitsky 1995), un victimario que declarando arrepentimiento testimonió su participación en actos criminales de represión, lo que produjo un gran impacto en los medios de comunicación y en la sociedad. Con estas novedades comenzó un período al que se caracterizó como el "boom de la memoria", porque nuevamente el terrorismo de Estado ocupó el primer plano en los medios masivos de comunicación con la particularidad de que esta instalación del tema se logró en contra de la política oficial, mediante la acción sobre la opinión pública de los organismos de derechos humanos.

El tratamiento del problema adoptó entonces características diferentes de las que había tenido desde que se reinstaló la democracia. Los desaparecidos ya no se describían como jóvenes víctimas inocentes sino como militantes, con un proyecto y una participación política concreta (O berti y Pittaluga 2007). En esos años, el interés por los '70 explotó y aparecieron numerosas publicaciones sobre distintos aspectos de aquel pasado, a la vez que se reeditaron varios libros que habían conseguido buenas ventas cuando se retiró la dictadura. Entre los nuevos, los más difundidos fueron El presidente que no fue (Bonasso 1997) y La voluntad (Anguita y Caparrós 1997), que también ponían en primer plano el tema de la militancia política.

Un último ciclo de la memoria se inició en 2006 con la conmemoración de los 30 años del golpe de Estado. En ese entonces, el presidente Kirchner transformó en política oficial esa narración gestada a mediados de los 90 e instaló un discurso reivindicatorio de las agrupaciones militantes, apoyado en decisiones simbólicas como disponer la fundación de un museo de la memoria en el edificio de la Escuela Superior de M ecánica de la Armada (ESM A). El fortal ecimiento de estos contenidos escolares dispuesto por la Ley General de Educación aprobada también en 2006 acompañó esas medidas. Consecuentemente, por el Día de la Memoria por la Verdad y la Justicia, todos los 24 de marzo la dictadura debería recordarse en la escuela. Pero una nueva memoria no desplaza totalmente a la anterior y las distintas narraciones conviven, guardando entre sí una relación similar a la de las capas geológicas, habilitando sentidos diferentes, combinados y hasta contrapuestos. 


\section{Las conmemoraciones escolares del 24 de Marzo}

El ámbito de nuestra observación de los actos escolares por el Día de la Memoria de 2008 fueron las escuelas de Educación Primaria de $M$ alvinas Argentinas. Este es uno de los 33 partidos que integran el Conurbano Bonaerense y, según los criterios utilizados para caracterizarlos, perteneciente al segundo cordón industrial.

Las cifras del Anuario 2002 de la Dirección Provincial de Estadística (el último publicado hasta la fecha por esa repartición) nos muestran que en M alvinas Argentinas la pobreza está por encima del promedio bonaerense. Las N ecesidades Básicas Insatisfechas (NBI) afectan al 19,8\% de los hogares - contra el $13 \%$ del total provincial- y el $22,9 \%$ de su población, frente a un 15,8\% para el mismo total. Por su parte, los Índices de Privación Material de los Hogares (IPMH), señalan que el $36 \%$ de los hogares del partido están incluidos en privación de recursos corrientes (contra un 30\% para el conjunto del Conurbano); mientras que en privación patrimonial, se incluye a un $32 \%$ de sus hogares, mientras que para la totalidad del Conurbano la tasa es menor: $22,5 \%{ }^{9}$.

Los niños que concurren a las escuelas primarias de gestión pública del distrito en buen número están afectados por estas carencias. De un total de 41 instituciones de este tipo relevamos las actividades realizadas por el Día de la Memoria en 29 de ellas, lo que representa casi un $71 \%$.

El Calendario Escolar de la Provincia de Buenos Aires define la condición de los actos escolares, que pueden ser "Solemnes", "Evocativos" o "Especiales". Al 24 de marzo le corresponde el carácter de "Evocativo" y se conmemora "en una hora de clase, con la presencia de todo el personal y alumnos de cada turno. Con apertura comunitaria"10. Por otro lado, en el anexo IV se enuncia un rígido protocolo que establece todos los pasos formales que deben respetarse en las conmemoraciones; mientras que en el VI se expone un cronograma que deben cumplir todas las escuelas - públicas y privadas- y los motivos por los que se recuerda cada fecha. En relación al 24 de marzo, establece que el objetivo de dicha evocación es: "Condenar toda usurpación de los poderes surgidos legítimamente por imperio de la Constitución, poniendo el acento en un conocimiento profundo de

9 www.ec.gob.gov.ar/Estadistica/FTP/anuario2002, consul tado el 4/4/2009.

$10 \mathrm{http://abc.gov.ar/escuelas/calendariosescolar/} \mathrm{marzo,} \mathrm{consultado} \mathrm{12/02/08.}$ 
lo establecido en los artículos $22^{\circ}$ de la Constitución Nacional y 30 de la Constitución de la Provincia de Buenos Aires (ambas reformadas en 1994). Por tanto se busca impulsar en la comunidad educativa actitudes de convivencia, caracterizadas por el respeto, la libertad y la tolerancia, pilares fundamentales de una sociedad plural, de clara raigambre popular y de fuerte contenido democrático. Consolidar la memoria colectiva de la sociedad, generar sentimientos opuestos a todo tipo de autoritarismo y auspiciar la defensa permanente del Estado de derecho y la plena vigencia de los derechos humanos. Las distintas ramas de la Educación adaptarán las mismas a las características de sus alumnos la forma 3-1"11.

\section{Recordando el golpe de Estado}

En 2008, el 24 de marzo tuvo la particularidad de ubicarse en el almanaque en el lunes siguiente a los feriados de Semana Santa. Esta circunstancia fortuita facilitó que en muchos casos la efemérides no fuera conmemorada siguiendo las directivas de la Dirección de Cultura y Educación: catorce de las escuelas relevadas no realizaron actos abiertos al público como se disponía oficialmente y se limitaron a presentar en los salones carteleras relacionadas y, en algunos casos, a tratar el tema en las aulas a puertas cerradas, sin participación de otros escolares que no correspondieran a ese curso; cuatro dieron lectura a un discurso en presencia de todos los alumnos y del personal del establecimiento pero sin apertura comunitaria y sólo once cumplieron estrictamente las directivas oficiales.

En términos proporcionales, del total de estas instituciones, aproximadamente el $62 \%$ no otorgó a la fecha la importancia que le deparaba el Calendario Escolar y sólo respetó las formas establecidas oficialmente un porcentaje cercano al 38\%. El discurso del docente designado para tal efecto resultaba la parte fundamental del acto y por esta razón analizaremos un corpus de trece alocuciones (las once correspondientes a los actos abiertos y dos de las cuatro que se realizaron en presencia de toda la escuela pero a puertas cerradas) para intentar determinar qué

11 http://abc.gov.ar/escuelas/calendariosescolar/marzo, consultado 12/02/08. El formato 3-1 refiere a un acto evocativo en la primera o última hora de clases, con la presencia de alumnos y abierto a la comunidad. Para 2009 el acto presenta una inesperada modificación, ya que se elimina para ese año lectivo la convocatoria comunitaria. 
Gonzalo deAmézola y Claudia D'Achary

representaciones de la memoria colectiva estuvieron presentes en ellos. Estos trece discursos representan casi un $32 \%$ de todas las escuelas del Partido. Sin duda, los discursos no expresan la totalidad de sentidos que se transmiten en un acto escolar pero sí uno que a nosotros nos interesa especialmente en este trabajo: condensan las representaciones del imaginario de los docentes acerca de la dictadura militar de 1976-1983.

\section{a. El período considerado}

En sólo una de las alocuciones analizadas existe referencia a acontecimientos previos al 24 de marzo de 1976:

“La presidenta M aría Estela M artínez de Perón había sido depuesta y una Junta de Comandantes 'gobernaba' en nombre del Proceso de reorganización $\mathrm{N}$ acional un país que atravesaba una crisis de gobernabilidad con inflación, enfrentamientos muy serios entre sindicatos y violencia de Estado representada por la Alianza Anticomunista Argentina" (Discurso "E").

En todas las demás exposiciones se considera que el golpe de Estado quiebra una continuidad con la realidad preexistente, pero sin realizar referencia alguna a acontecimientos anteriores que pudieran explicarlo o considerarse antecedentes:

"La última dictadura militar marcó una fractura profunda en el devenir histórico argentino, hay una Argentina anterior a 1976 y otra posterior a 1983" (Discurso "A").

"Hoy nos reunimos para recordar una muy triste fecha que prevalece en los corazones de todos. El 24 de marzo de 1976, al anochecer, si bien se presumían novedades tristes, nadie pensaba en la larga noche que se cernía sobre los argentinos" (Discurso "K").

\section{b. Causas del golpe de Estado}

En consecuencia, los discursos no plantean causas para la interrupción del orden constitucional, a excepción del párrafo transcripto del discurso "E" que afirma que la ingobernabilidad durante el gobierno de Isabel Perón explica el cuartelazo. En siete de las demás exposicio- 
nes se habla de - 0 se da a entender- una conspiración militar sobre la que no se brindan justificaciones, como ocurre en este ejemplo:

“El día de ayer, '24 de marzo' no fue un día más, fue un día destinado a la reflexión y a la memoria de todos los argentinos, ya que se cumplieron 32 años de aquel 24 de marzo de 1976, cuando las fuerzas armadas asumieron el poder político por la fuerza con el absurdo pretexto de llevar a cabo una 'Reorganización Nacional'" (Discurso "B").

En el resto, el golpe de Estado se toma como un hecho natural que no merece explicarse.

\section{c. El terrorismo de Estado}

El tema excluyente de los discursos es, naturalmente, el terrorismo de Estado. No hay referencias a otras cuestiones, como la política económica o la guerra de Malvinas. En la caracterización de quiénes fueron objeto de esta represión no existe ningún ejemplo en el que se condene a los "delincuentes subversivos" como ocurría en el relato que instaló la dictadura. Tampoco se habla de "militantes políticos" - como en las narraciones predominantes desde mediados de los años 90- aunque en un caso, la relación entre activismo político y secuestro aparece en forma velada:

"Mucho se ha dicho acerca de las cotidianas no-noticias (sic) que en esa triste época de la historia reciente daban cuenta de la aparición de cientos de muertos jóvenes, hombres y mujeres que, con alto sentido de compromiso cívico hacían de la política una práctica cotidiana y solidaria" (Discurso "K").

La identificación de los desaparecidos en los demás discursos es como "víctimas inocentes" que ansiaban vivir en democracia:

"Entre las víctimas del Proceso figuran mujeres, niños, ancianos, médicos, abogados, científicos, obreros, sacerdotes, etc." (Discurso "I").

“Este gobierno concretó dos planes siniestros: primero, el secuestro y la desaparición de adultos de diferentes clases sociales y segundo la apropiación de niños. Desaparecieron 30.000 perso- 
Gonzalo deA mézola y Claudia D’Achary

nas y 500 niños fueron robados a sus mamás e incorporados a otras familias ajenas, sin contarles la verdad sobre su origen y procedencia" (Discurso " $F$ ").

"Como argentinos debemos recordar lo que sucedió hace 32 años en nuestro país, ese es nuestro pasado en el que 30.000 hermanos han desaparecido queriendo ejercer su derecho de vivir en democracia, eligiendo un gobierno que los represente y respete a cada ciudadano" (Discurso "G", subrayados en el original).

\section{d. El papel de la sociedad}

En lo que se refiere al rol de la sociedad civil frente al golpe de Estado, las posiciones son variadas. D entro de los trece discursos analizados, encontramos uno que considera existía un consentimiento inicial para la interrupción del régimen constitucional:

“(...) en aquel momento, importantes sectores apoyaban este golpe militar, mientras que el pueblo harto de un mal gobierno y de la violencia cotidiana pensaba que un 'gobierno de orden' traería las soluciones esperadas" (Discurso "B").

En otro caso se hace referencia a sectores cómplices de los militares:

“Pero es nuestra obligación, cada año, recordar aquella fecha triste para que nunca vuelva a ocurrir en estas tierras el dominio de la barbarie. El dominio de la fuerza brutal de aquel grupo de militares. $\mathrm{Ni}$ de aquellos civiles que acompañaron a la barbarie, aportando ideas y rostros para la ejecución de políticas sociales, culturales y económicas destructivas" (Discurso "K").

En un tercer caso se habla de actitudes muy variadas:

"Algunos apoyaron ese sistema [desapariciones y torturas], otros buscaron justificaciones del horror, otros trataron de no ver, muchos sólo pudieron callar y muchos otros resistieron y lucharon para restablecer la plena vigencia de los derechos humanos en nuestro país" (Discurso “L”).

En las diez alocuciones restantes la sociedad es presentada como ignorante de lo que realmente ocurría, como en el caso siguiente: 
“Estábamos demasiado ocupados trabajando y criando a nuestros hijos y los días transcurrían con la llegada de algunas noticias descolgadas que nos Ilenaban de interrogantes. ¿D ónde está (...)? La gente desaparecía o 'se suicidaba', algunos jóvenes vecinos eran llevados para ser interrogados y no volvíamos a saber de ellos. ¿Dónde estarán detenidos?, nos preguntábamos.

Escuchábamos en las noticias que gente organizada con nombres como 'ERP' o 'Montoneros' se enfrentaba con las fuerzas armadas y los diarios hablaban de aplastantes triunfos militares y de la muerte de miles de subversivos.

También nos enterábamos que explotaban bombas en los colectivos o debajo de la cama de una niña de quince años hija de un al to mando militar o de desapariciones por ambos bandos.

Vivíamos en la confianza de que nada nos pasaría porque nos dedicábamos, como dije, a trabajar y a formar una familia (...)" (D iscurso "E").

\section{e. Las conclusiones sobre la experiencia de la dictadura}

La finalidad ejemplar de los actos está determinada en el mismo calendario escolar, pero la enseñanza que deja la experiencia de la dictadura en estos discursos presenta matices. En todos los casos, se plantea la necesidad de "recordar para que no vuelva a ocurrir" y también, para "hacer justicia", aunque esto último es sostenido con distintos grados de firmeza:

“Esta fecha debe servir para recordar lo que nunca debió haber sido.

Y también para permanecer alertas por si alguna vez 'alguien' que se crea iluminado por vaya a saber qué fuerza sobrehumana, cree que su razón puede imponerse sobre los demás, bajo el filo de una bayoneta o la descarga de una picana artera" (Discurso "K").

“Entonces, usemos la memoria para recordar lo feo y triste que fue, la memoria nos sirve para recordar lo malo que se hizo y para exigir que no vuelva a pasar. De los errores se aprende. No digamos más 'por algo le pasó'. No digamos más que esa época fue mejor" (Discurso "F"). 
Gonzalo deA mézola y Claudia D'A chary

"Es un deber de todos recordarlos, tanto a las víctimas como a los culpables. A los primeros, para que su lucha, su muerte no sea en vano y a los segundos para que paguen su deuda con la sociedad. Por esto es importante mantener la memoria viva, porque la verdadera muerte es el olvido y para que hechos de esta naturaleza no ocurran nunca más" (Discurso "I").

En siete discursos, la reivindicación del sistema democrático de gobierno se presenta como la barrera eficaz para los atropellos a los derechos humanos:

"Los gobiernos de estas características, impuestos por la fuerza de las armas y no elegidos por el voto, se especializan en perseguir todo pensamiento distinto. (...) En cambio, cuando hablamos de un gobierno democrático decimos que el mismo es ejercido por el pueblo a través de sus representantes, que elegimos para que cumpla con la voluntad de la mayoría y se respeten los derechos de todos, tenemos libertad de opinión y de acción" (Discurso "D").

En uno de los casos, el "deber de memoria" es defendido como algo permanente y vinculado con la actualidad para la escuela donde se desarrolla el acto:

"Hoy hay personas a las que les molesta que se hable de estas cosas. Dicen que son cosas del pasado y que sólo deberíamos mirar hacia el futuro. Nosotros pensamos que es necesario oponernos con todas nuestras fuerzas al olvido. Por eso, del Golpe no hablaremos sólo hoy: durante el año habrá muchos eventos y situaciones para construir memoria. Cada uno de ellos permitirá que ustedes conozcan los reclamos por verdad y justicia encabezados por los organismos de derechos humanos, que participen del rechazo a la violencia del Estado sobre la población, que aprendan que los derechos humanos se vulneran todavía hoy, cuando las personas sufren diversas formas de exclusión, de indignidad y de muerte" (Discurso "L").

\section{Algunas líneas de discusión}

¿Qué representaciones de la memoria circulan por el ámbito escolar, según los indicios que nos presentan estos discursos? En primer 
lugar, la creación misma del Día de la Memoria pone fuera de juego a la "teoría de la conciliación nacional" del menemismo. Por la misma razón, las narraciones justificatorias del golpe de Estado divulgadas durante la dictadura están naturalmente ausentes: no hay referencias a una "guerra sucia" anterior al 24 de marzo ni de los desaparecidos como "delincuentes subversivos". No era tan previsible, sin embargo, que estuviera ausente en estas intervenciones toda alusión reivindicando a las agrupaciones militantes de los años '70, tal como consagró el último ciclo de las políticas de la memoria.

En los casos examinados predomina fuertemente la narración del $\mathrm{N}$ unca Más. En todos ellos los desaparecidos se consideran como víctimas inocentes y se los caracteriza por su edad, género y ocupación pero no por su militancia política. Este hecho explica que el análisis comience el 24 de marzo de 1976 y no antes. Esa identificación de los desaparecidos fue, como dijimos, una respuesta al relato de los dictadores, que justificaban las desapariciones como los efectos colaterales y no queridos de la "guerra sucia". Por el contrario, para estos discursos la explicación se encuentra en los resultados de un plan brutal de represión dirigido contra ciudadanos inocentes, coincidiendo con la versión instalada por el informe de la CON ADEP.

Asimismo, el papel predominante atribuido a la sociedad durante la dictadura es el de la denominada "teoría de los dos demonios": la violencia que se propagó en Argentina durante los años '70 era resultado de dos terrorismos producidos por posturas ideológicas antagónicas, el de las Fuerzas Armadas y el de las organizaciones guerrilleras. La sociedad resultaba ajena a esos extremismos y había quedado trágicamente encerrada en ese fuego cruzado, del que no era más que una víctima. Por eso reclamaba orden, pero desconociendo lo que realmente ocurría con el atropello a los derechos humanos. Si se apoyó en al gún momento al golpe de Estado era por ese deseo de regreso a la normalidad pero se ignoraba la sanguinaria represión que había desatado la dictadura porque, de haberlo sabido, jamás la hubiera tolerado. La "teoría de los dos demonios" servía - en consecuencia- para lavar la culpa colectiva y cohesionar a la sociedad mediante una memoria que la habilitaría a eludir todo grado de responsabilidad en la violencia de los años ' 70 en un nuevo modelo de convivencia. Como dicen Lvovich y Bisquert: "La violencia política y el terrorismo de Estado no tendrían cabida en este nuevo período en el que la democracia, respetuosa de los derechos elementales de todos los ciudadanos, permitiría la civilizada coexis- 
tencia de distintas posturas ideológicas. La idea de revolución quedaba así neutralizada en sí misma en la medida que perdía su razón de ser: no había necesidad alguna de que jóvenes idealistas se rebelaran en contra de un sistema fundado en principios republicanos y democráticos, y en la legalidad y la defensa de los derechos humanos. Por su parte, el terrorismo de estado, que se tornó visible en toda su magnitud y crueldad (...) fue condenado moralmente primero [en el informe de la CO N ADEP] y a nivel judicial después [por el juicio a las juntas militares]" (Lvovich y Bisquert 2008:36-37).

Ciertamente, estas representaciones no aparecen en los discursos en una forma "pura" y las provenientes de las otras etapas de la memoria colectiva las "contaminan", aunque no empalidecen su marcado predominio. Además, aunque la fuerza narrativa de la explicación del Nunca Más fue perdurable, esto no significa que sus imágenes de la dictadura se mantuvieran inmutables a través del tiempo sino que, por el contrario, su contenido fue resignificándose por nuevas lecturas en estos veinticinco años. Como dice Emilio Crenzel: "Los diversos usos del Nunca Más, así como el de los perpetradores [de la represión] por impugnarlo mediante libros que escribieron específicamente con este fin, ilustran el extendido reconocimiento público por su carácter canónico. Sin embargo, al mismo tiempo, sus diversas resignificaciones muestran que no fue ajeno a los tiempos políticos de la memoria colectiva, hecho que se desprende, también, del perfil y las interpretaciones de sus lectores recientes sobre su significado" (Crenzel 2008:190). De todas maneras, en los discursos analizados, la perspectiva de los docentes es muy cercana a la interpretación más tradicional del informe.

¿El caso de los maestros de Malvinas Argentinas se explicará porque han leído el informe de la CONADEP? Es improbable, pero los relatos sobre el pasado dictatorial se han transmitido por muy diversas vías, dentro de las cuales los medios masivos de comunicación -en especial la televisión- han cumplido un rol potente durante este cuarto de siglo y en esa difusión la perspectiva original del Nunca Más tuvo un papel privilegiado (Crenzel 2008). Por otra parte la generalidad de los docentes argentinos no ha estudiado esos contenidos en su escuela secundaria ni en su formación posterior, razón por la cual estas vías no convencionales de información ocupan un lugar de importancia. Por todo ello, afirma María Paula González, es “(...) interesante analizar cómo, con qué referencias y con qué estrategias los profesores 'reparan, remiendan y arreglan' estos vacíos y silencios para hacer frente a 
la demanda de recordar y enseñar que actualmente tiene la escuela secundaria" (González 2005).Esta es una afirmación que puede trasladarse aún con mayor fuerza, a la educación primaria, ya que en este ámbito el papel de los medios de comunicación masiva es (y ha sido) muy importante en la formación de la opinión de los docentes.

En nuestro caso, un interesante "remiendo" se puede comprobar en cuatro discursos que resultan prácticamente idénticos. El origen de todos ellos fue el modelo de disertación que para el caso apareció en el número de marzo de 2008 de la revista Maestra de Segundo Ciclo de la editorial EDIBA (2008:22), el que en su primer párrafo dice: "Recordar el golpe militar del 24 de marzo de 1976 invita a reflexionar sobre nuestra responsabilidad como ciudadanos y cuanto menos, sobre cómo pudimos permanecer sin reaccionar mientras se nos rebanaba el futuro de todo el país. Nos costó darnos cuenta de lo que sucedía, de cómo se precipitaban los hechos y, por supuesto nos quedamos inermes, no para actuar con violencia, pero si con presencia".

En el discurso " $\mathrm{H}$ ", el párrafo se reprodujo textualmente y sólo se procedió a eliminar algunos de los subsiguientes para que resultara más breve. Algo parecido ocurre en el " $\mathrm{C}$ ", que abrevia también ese comienzo en su afán de resumir. En los otros dos casos, la propuesta de Maestra de Segundo Ciclo fue leída textualmente de principio a fin. U na de estas docentes lo hizo directamente con la revista en mano, mientras que la segunda tuvo la delicadeza de fotocopiarla. Este hecho presenta un aspecto interesante para reflexionar: casi uno de cada tres de los maestros que habló públicamente en los actos que observamos delegó su opinión - que se consideraba rectora en la "construcción de la memoria"- en la salida rápida que le ofrecía un material ya preparado por una publicación que ofertaba un discurso lo suficientemente ambiguo e indeterminado como para que pudiera reproducirse en cualquiera de las heterogéneas escuelas argentinas.

Pero la influencia de la revista no se limita a los discursos. Su intención de facilitar la tarea de los maestros se extiende a propuestas de ornamentación escolar y áulica, salones, pasillos, carteleras y telones para la fecha, además de indicar actividades para que realicen los alumnos. En las escuelas relevadas se registraron muchas de estas propuestas. Fue especialmente exitosa la cartelera con una imagen de la Pirámide de Mayo, rodeada por dibujos de los emblemáticos pañuelos de las Madres de Plaza de Mayo. Bajo el título de "Este 24 de marzo renovemos (...)" podían leerse distintas leyendas escritas 
sobre los pañuelos que completaban aquella frase: "El respeto por la vida", "Las ganas de participar", "N uestras esperanzas", "N uestras ilusiones", "Nuestro optimismo", "Nuestros esfuerzos", "El respeto por los derechos humanos", "N uestras alegrías", etc. Además, otras instituciones utilizaron las mismas siluetas como imagen representativa del momento pero introduciendo una modificación al ofrecer a los niños escribir sobre los pañuelos sus propias palabras.

A primera vista, estas posiciones se contraponen con el "deber de memoria" del discurso "L", pero en este caso existe también un modelo que se reproduce casi literalmente: el texto enviado por la Secretaría de Educación de la ciudad de Buenos Aires para ser leído en sus escuelas en la primera recordación del Día de la Memoria en 2006.

¿Por qué en la mayoría de las escuelas las autoridades no le dieron al 24 de marzo la importancia que le otorgaba el calendario escolar? ¿Por qué una buena parte de los docentes transformó su participación en algo vacío de compromiso personal? Si bien la ocasión de que el día fuera precedido por los feriados de Semana Santa alejaba a la efemérides de su recordatorio, si el almanaque ubicara en una situación tan particular al Día de la Bandera zalguna escuela de Malvinas Argentinas hubiera relativizado la importancia de esta ceremonia? Pensamos que no. El fenómeno de la elusiva conmemoración del golpe de Estado en 2008 se debe, sin duda, a muchas razones pero una de ellas está vinculada a lo que se ha dado en Ilamar la "cultura escolar". Según Antonio Viñao, la cultura escolar "(...) estaría constituida por una serie de teorías, ideas, principios, normas, rituales, inercias, hábitos y prácticas (formas de hacer y pensar, mentalidades y comportamientos) sedimentadas a lo largo del tiempo en forma de tradiciones, regularidades y reglas de juego no puestas en entredicho, y compartidas por sus actores, en el seno de las instituciones educativas. (...) La cultura escolar sería, en síntesis, algo que permanece y que dura; algo que las sucesivas reformas no logran arañar más que superficialmente; que sobrevive a ellas, y que constituye un sedimento formado a lo largo del tiempo" (Viñao 2002:73-74).

En consecuencia, la escuela que desde siempre se ocupó de evocar el pasado glorioso de la patria para formar el carácter de los niños con el ejemplo de la conducta de los héroes, recibe el mandato de conmemorar al 24 de marzo invirtiendo dramáticamente ese modelo: hay que recordar las acciones miserables y despiadadas de los dictadores para aprender a no repetir ese pasado vergonzoso. Esta modifi- 
cación de las reglas pone a la escuela en una tensión que para muchos es insoportable y no son pocos los que la solucionan con la omisión o la banalización del compromiso. También la cultura escolar limita el espectro de memorias de posible circulación en las aulas. La escuela puede reivindicar a las víctimas inocentes, pero ¿podría exaltar las acciones armadas de la guerrilla, siguiendo el último ciclo de las políticas oficiales de la memoria? Viñao distingue diversas culturas entre los diferentes actores educativos (docentes, padres, alumnos) y determina aún dentro de ellos distintas subculturas. Plantea además una contradicción que pensamos interesante para reflexionar sobre nuestra descripción de los modestos resultados de la conmemoración del Día de la memoria en 2008. El autor habla de una “(...) doble interacción, y enfrentamiento, entre la cultura de los profesores y maestros con la cultura de los reformadores y gestores y la de los expertos o científicos de la educación - siempre tentados, cuando las condiciones políticas lo permiten, a convertirse en reformadores- es la que explica en buena parte el fracaso de las reformas educativas" (Viñao 2002:81).

A esta cuestión podemos agregarle otra. En un artículo publicado en 1999 (Amézola 1999) uno de los autores de estas páginas advertía sobre un tema que parecía no haberse tenido en cuenta entonces, cuando se decidió enseñar historia del tiempo presente en la escuela media: lo que era reciente para el profesor no lo era para sus alumnos y esta "brecha invisible" entre ambos era una dificultad considerable para ocuparse de estos temas. Hoy, una lógica elemental indica que muchos de aquellos profesores que vivieron la dictadura en carne propia se deben de haber jubilado y que una cantidad apreciable de esos alumnos de 1999, para los cuales el período de 1976-83 pertenecía a un pasado brumoso, pueden ser los docentes que están al frente de cursos como los que observamos en Malvinas Argentinas. De hecho, las vivencias personales acerca del golpe de Estado están presentes sólo en el discurso "E". La brecha ahora resultaría distinta y se ubicaría entre el currículo prescripto y el calendario escolar que ordenan hablar de la dictadura militar, por una parte, y, por la otra, los docentes, cuya formación secundaria y terciaria no los instruyó en un tema que, además, no ha resultado para ellos en lo personal una experiencia traumática. La motivación y los conocimientos para que estos profesores se ocupen de la "formación de la memoria colectiva", como establece la nueva Ley de Educación, no están en la mayoría de los casos a la altura del desafío. Por este motivo, las recetas estereotipadas que ofre- 
cen revistas como Maestra de Segundo Ciclo les brindan una solución que aprovechan para encarar un tema que les resulta desconocido e incómodo. Hablando de la Segunda Guerra, Eric Hobsbawm plantea una reflexión que nos resulta muy sugestiva aplicada a este fenómeno: "No hay ningún país donde al desaparecer la generación política que tuvo experiencia directa de la segunda guerra mundial, no se haya producido un cambio importante, aunque a menudo silencioso, en su política, así como en su perspectiva histórica de la guerra (...) Esto es aplicable, de modo más general, al recuerdo de los grandes cataclismos y traumas de la vida nacional" (Hobsbawm 1998:135).

La Ley Nacional de Educación promueve generar en los alumnos "reflexiones y sentimientos democráticos", pero es imposible hacer reflexionar sobre lo que se desconoce. Por eso, entre ambas cuestiones las escuelas cuyas conmemoraciones observamos han optado por el sentimiento y, las más de las veces, por un sentimentalismo que resulta superficial o retórico. La reflexión hace imprescindible discutir ideas, lo que choca también con una tradición arraigada en las escuelas de América Latina, donde se considera a la controversia como un ejercicio intelectual pernicioso. Por supuesto, hablamos de que los maestros hagan pensar a sus alumnos según las posibilidades de su edad, pero es necesario ocuparse de ello porque a pensar se aprende paso a paso. Si no se produjera esa reflexión, la consecuencia no querida que una mirada superficial puede producir es que el recuerdo de la dictadura se transforme en una simple "película de terror" donde un grupo de monstruos, sin ninguna conexión con el resto de población, atormenta a la sociedad obedeciendo sólo a su maldad intrínseca. Por el contrario, deberíamos intentar aproximar el tema a los difíciles términos en que lo planteó Primo Levi: "Q uizá no se pueda comprender lo que sucedió o no se deba comprender lo que sucedió, porque comprender es justificar. No podemos comprender el odio nazi, pero podemos comprender dónde nace ese odio" (Abós 1997:17).

En consecuencia, estas carencias deberían atenderse con un esfuerzo intenso en programas de actualización en contenidos y metodologías de enseñanza para los docentes en ejercicio. En 2006, cuando se instaló el 24 de marzo en el calendario escolar, el Ministerio de Educación lanzó el programa "A 30 años del golpe" que organizó -entre otras cosas- un concurso de monografías entre los escolares. Existen algunos otros como "Jóvenes y Memoria" de la Comisión Provincial 
por la Memoria ${ }^{12}$ o los cursos de Memoria Abierta ${ }^{13}$. Sin embargo, esas actividades, aunque valiosas, son insuficientes. El carácter voluntario de su participación presenta la paradoja de que sólo intervienen en ellos los docentes previamente interesados y que ya otorgan relevancia a esos contenidos en el aula. Sería necesario, entonces, promover para todos lineamientos de trabajo amplios que se propongan superar la transmisión de una perspectiva congelada, basada sólo en el sentido común bienpensante, y que esas propuestas logren motivar a la mayoría de los docentes.

\section{Referencias bibliográficas}

Abós, Álvaro. "La ardiente paciencia". Diario La Nación, 18 de julio de 1997.

Amézola, Gonzalo de. "Problemas y dilemas en la enseñanza de la historia reciente". Entrepasados, no 17, 1999:137-164.

Anguita, Eduardo y Martín Caparrós. La voluntad. Tomo I. Buenos Aires: Norma, 1997.

Bonasso, Miguel. El presidente que no fue. Buenos Aires: Planeta, 1997.

Cerruti, Gabriela. "La Historia de memoria. Entre la fetichización y el duelo". Revista Puentes. Especial 25 años. Año 1, n 3, 2001:2022.

Costa, Flavia. "O bsesionados por recordar. Entrevista con Andreas Huyssen". Diario Clarín. www.clarin.com. 27/4/2002. Consultado el 3/10/2009.

Crenzel, Emilio. Historia política del Nunca Más. Buenos Aires: Siglo XXI, 2008.

Feld, Claudia. "Entrevista con Henry Rousso. 'El duelo es imposible y necesario'". Puentes, no 2, 2000.

González, M aría Paula. "La historia argentina reciente en la escuela media: entre deberes, problemas y posibilidades". Actas de las

12 Cfr: www.comisionporlamemoria.org.

13 Cfr. www.memoriaabierta.org.ar. 
X Jornadas Interescuelas/Departamentos de Historia. CD-Rom. U niversidad N acional de Rosario, 2005.

Hobsbawm, Eric. "El presente como historia", en: E. Hobsbawm, Sobre la Historia. Barcelona: Crítica, 1998.

Jelin, Elizabeth. Los trabajos de la memoria. Buenos Aires: Siglo XXI, 2002.

Kosellek, Reinhart. Los estratos del tiempo: estudios sobre la historia. Barcelona: Paidós/I.C.E.U .A.B., 2001.

Lorenz, Federico. "'Recuerden argentinos' por una revisión de la vulgata procesista". Entrepasados, no 28, 2005:65-82.

Lvovich, Daniel y Jacquelina Bisquert. La cambiante memoria de la dictadura. Los Polvorines: U N G S/Biblioteca Nacional, 2008.

O berti, Alejandra y Roberto Pittaluga. Memorias en montaje. Buenos Aires: El Cielo por Asalto, 2007.

Prost, Alain. "D ossier Historia y memoria de las dos guerras mundiales. ¿Educar en la memoria?". Traducción de Fernando Hernández Sánchez en http://clio.rediris.es.

Ricoeur, Paul. La memoria, la historia, el olvido. Buenos Aires: FCE, 2004.

S/D. "24 de marzo: Día de la Memoria, Verdad y Justicia". Revista Maestra de segundo ciclo. Editorial EDIBA, 2008.

Verbitsky, Horacio. El vuelo. Buenos Aires: Planeta, 1995.

Vezzetti, Hugo. Pasado y presente. Guerra, dictadura y sociedad en la Argentina. Buenos Aires: Siglo XXI, 2002.

-__. Sobre la violencia revolucionaria. Buenos Aires: Siglo XXI. 2009.

Viñao, Antonio. Sistemas educativos, culturas escolares y reformas: continuidades y cambios. Madrid: M orata, 2002. 


\section{Resumen}

Este artículo se ocupa del problema del tratamiento del pasado reciente en la escuela. Describe las distintas representaciones de la última dictadura militar que se encuentran presentes en los discursos pronunciados en las conmemoraciones realizadas en 2008 para recordar el golpe de Estado del 24 de marzo de 1976 en escuelas primarias del partido de Malvinas Argentinas, ubicado en el Conurbano Bonaerense. Se analiza en esos discursos la presencia de distintas narraciones de la memoria colectiva.

Palabras clave: Escuela, dictadura militar, pasado reciente, memoria colectiva.

Memories to assemble. The commemorations of the March 24, on primary schools located near of Buenos Aires

\section{Summary}

This article focuses on the problem of the approach to the recent past in schools. It describes the different representations of the military dictatorship in the speeches made in 2008 to remember the coup d'etat of 24 march 1976 in the M alvinas Argentinas party, located near Buenos Aires. The presence of different narrations from the collective memory is analized in those speeches.

Key words: School, military dictatorship, recent past, collective memory.

Recibido: 24/04/09; aceptado: 18/08/09. 